\section{Level of arousal during Stroop performance: Effects of speed stress and "distraction"}

\author{
RICHARD I. THACKRAY and KAREN N. JONES* \\ Civil Aeromedical Institute, FAA, Oklahoma City, Okla. 73125
}

Heart rate and respiration were obtained during Stroop performance Although the test is of ten reported to evoke strong feelings of frustration, no evidence of increased autonomic arousal was found to be associated with the color-word interference effect, and this did not change with the addition of auditory "distraction." Increasing stimulus presentation rate increased arousal, but this was independent of color-word interference.

Although it has been reported that performance on the Stroop color-word interference test is accompanied by behavioral signs of tension and frustration (Klein, 1964), little information exists as to the actual extent of physiological arousal which results. In one of the few studies in which physiological measures have been taken, Frankenhaeuser et al (1967) found elevated skin conductance and catecholamine levels during Stroop performance, suggesting that the test does increase physiological arousal. However, the procedure they employed involved rapid presentation of conflicting auditory stimuli simultaneously with the visual and it is not clear from their data how much of the obtained increase in physiological activity was the result of the basic color-word interference effect and how much may have resulted from the auditory distraction and task pacing.

The present study, which formed part of a larger research program concerned with distraction susceptibility, employed a design similar to that used by Frankenhaeuser et al and was conducted in an attempt to determine the extent of autonomic arousal associated with the Stroop color-word interference effect and to clarify the influence of both irrelevant auditory stimuli and stimulus presentation rate on arousal and performance. A subsidiary aspect of the study was concerned with the question of whether or not the Stroop effect would be eliminated if the "colors" and "words" of the color-word stimuli were simultaneoulsy presented to separate sense modalities.

$$
\text { METHOD }
$$

Fifty paid male college students between the ages of 18 and 25 served as Ss. All were right-handed, with no reported color-vision deficiencies.

\footnotetext{
*The authors wish to express their appreciation to Robert $M$. Touchstone for his technical assistance with the instrumentation employed.
}

Each $S$ was assigned to one of five groups on a simple rotational basis, yielding a final $N$ of $10 \mathrm{Ss}$ per group.

The $S$ was seated in front of a console containing a rear projection screen and a Lafayette Model KT-800 automatic projection tachistoscope. His right hand rested on a shelf directly below four microswitch buttons with stimulus words printed directly above each. A speaker for presenting either task instructions or auditory stimuli was placed to the left of the projection screen.

The task programming equipment, as well as the equipment for recording the physiological and performance data, was located in an adjoining room. The method of programming the stimuli was as follows: Successive low-frequency pulses from an audio oscillator were initially recorded on one channel of a stereo tape recorder. The interval between pulses was a constant 3 sec. During playback, each pulse actuated a relay, which in turn triggered a bank of three timers. These activated the tachistoscope shutter and advanced the slides. Stimulus exposure was $1 / 2$ sec. The other channel of the tape recorder was used for instructions and for auditory stimuli.

Response time to each stimulus was measured to the nearest $1 / 100 \mathrm{sec}$ by means of a Welford Mark V SETAR (Welford Bioelectronics Enterprises) and was punched on paper tape. The tape was later fed through a Friden Flexowriter, which printed response time as well as recording which of the keys was pressed.

A Beckman Type R dynograph recorded the physiolgical variables. The electrocardiogram was obtained from Beckman biopotential electrodes attached to the lateral walls of the S's chest. Respiration was measured with a mercury-in-vinyl gauge attached at the abdominal level and connected to a specially constructed bridge coupler.

Visual stimuli were of three basic types: (1) the words BROWN, GREEN, ORANGE, or PURPLE, printed in black letters; (2) colored rectangles corresponding to the colors of these words; and (3) the above words printed in incongruent ink colors, e.g., the word BROWN would be printed in either green, orange, or purple ink. Stimuli were photographed and reproduced on $35-\mathrm{mm}$ slides. Stimuli were of constant height $(27 \mathrm{~mm})$ and width $(68 \mathrm{~mm})$, as projected on the screen. A small white cross on the screen served as a fixation point.

During Part 1, the Ss were told that each stimulus would consist of one of the following four words: brown, orange, green, or purple. Each time a stimulus was presented, he was to push the button corresponding to that word as rapidly as possible and then look back at the fixation spot. After every response, the $S$ rested his fingers on the shelf immediately below the buttons. Following four practice stimuli, the set of 72 stimuli, all printed in black letters, was presented. These were arranged in a quasirandom order, with the restrictions that each stimulus appear an equal number of times and that no two adjacent stimuli be the same. A 3-min rest period followed the last slide, which allowed time for the $E$ to change stimuli and make other necessary equipment adjustments. All Ss received the same stimulus order.

Part 2 was essentially the same as Part 1, except that the stimuli consisted of the colored rectangles and a different random order was used.

For Part 3a, each group received different stimuli and/or instructions. These were as follows:

Group $A$ received the same stimuli (colored rectangles) in the same order as they were presented in Part 2. They were told that the purpose of this part was to check the reliability of Part 2.

Group B was administered the set of stimuli employed with Group A, except that the name of one of the four colors was simultaneously spoken over the speaker each time a visual stimulus was presented. The $\mathbf{S}$ was instructed to ignore the spoken word and respond only to the color of the rectangle projected on the screen. The auditory stimuli were arranged in a quasirandom fashion similar to that employed with the visual stimuli. In every case, the auditory stimulus was the name of an incongruent color.

Group C was presented the conventional Stroop color-word stimuli, i.e., names of the four colors printed in incongruent inks. The Ss were instructed to ignore the word itself and respond only to the color of the word. In order to make conditions comparable to those for Groups $A$ and $B$, the order in which the colors of the stimulus words were arranged was the same as that of the colored rectangles used for Groups A and B. Likewise, the order of the words themselves was the same as that of the spoken words presented to Group B. 
Groups D and E used the same sequence of stimuli as were used with Group C. The difference was in the addition of auditory stimuli presented simultaneously with the visual. For Group D, these stimuli consisted of the names of the four colors which were always incongruent with both the projected word and its hue. For Group E, the auditory stimuli consisted of the following four randomly chosen numbers: $18,83,56$, and 25. Both groups were told to igrore the auditory stimuli and respond only to the color of the visually presented word. Randomization of the auditory stimuli was similar to that described previously.

As with Parts 1 and 2, the Ss in each group in Part 3 a received four practice trials and 72 visual stimuli (with or without auditory stimuli).

Following the completion of Part 3a, Ss in each group were informed that they would now be required to perform again the task they had just completed, only at a much faster pace (Part 3b). After four practice trials, each group received the same stimuli they were presented during the preceding part, except that the intertrial interval was reduced from $3 \mathrm{sec}$ to $1 \frac{1 / 2}{\mathrm{sec}}$.

\section{RESULTS}

Mean reaction times for Parts 2, 3a, and $3 \mathrm{~b}$ are shown in Table 1. An analysis of variance of Part 2 revealed no differences between the groups $(F=1.29, p>.05)$ in their response times to the colored rectangles. For Part 3a, however, the differences between the groups were significant ( $F=14.6, p<.01)$. A Newman-Keuls test (Winer, 1962) revealed that Groups $A$ and $B$ were different from Groups $C, D$, and $E(p<.01)$, but there were no significant differences between $A$ and $B$ or between $C, D$, and $E$. Presenting the stimuli at twice the initial rate resulted in no apparent change in the basic relationships between the five groups. The analysis of variance for $P$ art $3 b$ was significant $(F=12.56, \quad p<.01)$, and Newman-Keuls tests again revealed Groups A and B to differ from Groups $C$, D, and $E(p<.01)$ with no differences between $A$ and $B$ or between $C, D$, and $E$.

Mean levels of heart rate for all groups during Parts 2, 3a, and $3 b$ are shown in Table 2. A repeated-measures two-way analysis of variance revealed no significant differences between groups $(F=1.01, p>.05)$ and no significant interaction $(F=2.21$, $\mathrm{p}>.05$ ). There was, however, a highly significant difference between parts ( $F=44.97, p<.01$ ). The analysis of variance on the respiration data shown in Table 3 yielded similar results.
Table 1

Mean Response Time in Seconds for Each Group

\begin{tabular}{lccccc}
\hline & \multicolumn{5}{c}{ Group } \\
\cline { 2 - 6 } Part & A & B & C & D & E \\
\hline 2 & 0.78 & 0.73 & 0.85 & 0.80 & 0.80 \\
3a & 0.72 & 0.72 & 1.02 & 0.94 & 0.98 \\
3b & 0.76 & 0.74 & 0.95 & 0.86 & 0.90 \\
\hline
\end{tabular}

Table 2

Mean Heart Rate in Beats Per Minute for Each Group

\begin{tabular}{lccccc}
\hline & \multicolumn{5}{c}{ Group } \\
\cline { 2 - 6 } Part & A & B & C & D & E \\
\hline 2 & 72.4 & 79.3 & 79.0 & 74.4 & 68.5 \\
3a & 72.0 & $\mathbf{7 9 . 2}$ & $\mathbf{7 7 . 8}$ & $\mathbf{7 5 . 7}$ & $\mathbf{7 1 . 1}$ \\
3b & $\mathbf{7 5 . 1}$ & $\mathbf{8 3 . 4}$ & $\mathbf{8 1 . 7}$ & $\mathbf{8 2 . 6}$ & $\mathbf{7 6 . 3}$ \\
\hline
\end{tabular}

Table 3

Mean Respiration Rate in Cycles Per Minute for Each Group

\begin{tabular}{lccccc}
\hline & \multicolumn{5}{c}{ Group } \\
\cline { 2 - 6 } Part & A & B & C & D & E \\
\hline 2 & 20.5 & 18.8 & 18.2 & 18.9 & 20.2 \\
3a & 19.7 & 19.5 & 17.2 & 19.7 & 20.2 \\
3b & 22.7 & 22.0 & 19.0 & 23.1 & 23.5 \\
\hline
\end{tabular}

Thus, the difference between parts was quite significant $(F=34.96, p<.01)$, while neither the group $(F=1.15$, $p>.05)$ nor interaction $(F<1.00)$ effects were significant. Examination of Tables 2 and 3 clearly indicates that these significant effects were the result of the increase in both heart rate and respiration rate during Part $3 b$.

\section{DISCUSSION}

The results revealed that the method employed in this study for presenting the Stroop color-word stimuli was successful in eliciting the characteristic interference effect. However, there was no indication that the interference effect was accompanied by any change in heart rate or respiration rate. Also, neither the task-related (incongruent color names) nor the task-unrelated (random numbers) auditory stimuli had any apparent effect on either arousal or performance. The only change in arousal occurred as a result of the faster pace of Part 3b, in which uniformly higher levels of heart rate and respiration were obtained for all groups.

The failure of the irrelevant auditory stimuli to have an adverse effect on performance was not entirely unexpected, since several recent studies have found either no effect of miscellaneous noises on Stroop performance (Mandell, 1966) or a slight improvement in performance (Houston \& Jones, 1967). The fact that color-word interference was not accompanied by any increase in heart rate or respiration, however, was more of a surprise in view of the apparent frustration and tension noted earlier, which has been reported to attend Stroop performance, and in view of the elevated catecholamine levels found by Frankenhaeuser et al (1967), using a similar version of the Stroop test. However, in observing the behavior of the $S s$ in those groups receiving the color-word stimuli and in questioning them later, it appeared that they were often less emotionally "upset" than they were surpised and even somewhat amused at their difficulty in responding to the hue of the color-word stimuli. This suggests that the perceptual conflict produced by the Stroop stimuli may reflect attentional processes which are only minimally associated, if at all, with shifts in general level of "arousal." There is increasing evidence that changes in attentional demands may produce significant changes in task performance which are not accompanied by any observable shift in physiological indicants of activation (Malmo, 1966).

The present study suggests that the elevated catecholamine levels and increased skin conductance found by Frankenhaeuser and her coworkers may have been more the result of task pacing and/or the instructions employed than any "stress" resulting from the color-word interference itself. During Part 3b, Group D received essentially the same visual and auditory stimuli at approximately the same pace as employed by the above investigators. Yet, although both heart rate and respiration were increased by the more rapid rate of stimulus presentation, this increase did not differ from that of the control group that was administered the colored rectangles. Also, Frankenhaeuser et al administered instructions to their Ss, which implied that students in general were able to perform the task perfectly after some practice. Because of the frustrating nature of the task itself, such instructions could be quite threatening and might well have accounted for, or at least contributed to, the increase in physiological activity.

Finally, the data revealed the Stroop effect to occur only when both relevant and irrelevant stimuli were presented within the same (visual) modality. Thus, shifting the irrelevant stimuli to the auditory modality completely eliminated the interference effect. This finding would seem to support Treisman's (1969) recent conclusion that focusing upon one of several different stimulus dimensions within a given modality is a far more difficult task than focusing upon a 
particular sensory input and that it probably involves quite different attentional mechanisms.

REFERENCES

FRANKENHAEUSER, M., FRÖBERG, J. HAGDAHL, R., RISSLER, A. Physiological, behavioral, and subjective indices of habituation to psychological indices of habituation to psychological 229-237.

HOUSTON, B. K., \& JONES, R. M Distraction and Stroop color-word performance. Journal of Experimental Psychology, 1967, 74, 54-56.
KLEIN, G. S. Semantic power measured through the interference of words with color-naming. American Journal of Psychology, 1964, 77, 576-588.

MANDELL, $S$. J. Children's resistance to competing and distracting stimuli in the classroom. (Doctoral dissertation, University of Southern California.) Ann Arbor, Mich: University Microfilms, 1966. No. 66-11, 578 .

MALMO, R. B. Cognitive factors in impairment: A neuro-psychological study of divided set. Journal of Experimental Psychology, 1966, 71, 184-189.

TREISMAN, A. M. Strategies and models of selective attention. Psychological Review, $1969,76,282-299$.

WINER, B. J. Stotistical principles in experimental design. New York: McGraw-Hill, 1962.
It was not clear from the literature on the effects of social isolation and satiation (cf. Eisenberger, 1970; Gewirtz, 1967) what results should have been expected as a function of that factor. However, Lindskold \& Tedeschi (1971), using the semantic differential (Osgood, Suci, \& Tannenbaum, 1957), found that a promisor who kept his promises was perceived as evaluatively better (i.e., wiser, more honest, more kind, and more good) than a promisor who kept his promises infrequently. The present experiment was conducted in an attempt to replicate this finding and to investigate the influence of social deprivation and satiation on impression formation.

\section{SUBJECTS}

A total of 32 male Ss, who participated for extra credit, were signed up in pairs at the United States International University in the spring of 1970 . Ss were led to believe that they were participating with a peer other than the one with whom they signed up. In fact, the "other" person was simulated by the $\mathrm{E}$.

\section{PROCEDURE}

The $E$ asked the first $S$ who arrived to wait a few minutes in the waiting room. There a male confederate engaged the $S$ in conversation for a period of $10 \mathrm{~min}$, during which time, verbal and nonverbal responses of support, approval, and agreement were emitted in order to satiate. the $S$ to social reinforcement. 1 The second $S$ to arrive was left alone in a cubicle for $30 \mathrm{~min}$. Isolated $\mathrm{Ss}$ were directed to the experimental room by intercom and did not contact any other person en route.

When Ss entered the experimental room, they were confronted with the PD apparatus, which is more fully described elsewhere (Horai \& Tedeschi, 1969). The Ss were observed through a one-way mirror; when seated, they were instructed by tape recording to read the printed instructions provided and to signal when finished by saying, "OK." When the $S$ was ready, the instructions were thoroughly reviewed by tape recording and PD play began. The instructions explained the rudiments of $P D$ play, the matrix values (i.e., $R=4, T=5$, $S=-5$, and $P=-4)$, and the prerogatives of the other person to send the displayed message: "If you make Choice 1 on the next trial, I will add 10 points to your counter." Promises were sent to $S$ s intermittently over the course of 150 iterations of PD play. The SP played a preplanned, but randomized, $50 \%$ cooperative strategy. On promise-relevant trials, the SP was always cooperative, ensuring that the $S$ 